\title{
AN AERIAL RADIOLOGICAL SURVEY OF THE DOUBLE TRACK SITE AND SURROUNDING AREA
}

CENTRAL NEVADA 


\section{DISCLAIMER}

This report was prepared as an account of work sponsored by an agency of the United States Government. Neither the United States Government nor any agency thereof, nor any of their employees, make any warranty, express or implied, or assumes any legal liability or responsibility for the accuracy, completeness, or usefulness of any information, apparatus, product, or process disclosed, or represents that its use would not infringe privately owned rights. Reference herein to any specific commercial product, process, or service by trade name, trademark, manufacturer, or otherwise does not necessarily constitute or imply its endorsement, recommendation, or favoring by the United States Government or any agency thereof. The views and opinions of authors expressed herein do not necessarily state or reflect those of the United States Government or any agency thereof. 


\section{DISCLAIMER}

Portions of this document may be illegible in electronic image products. Images are produced from the best available original document. 


\title{
AN AERIAL RADIOLOGICAL SURVEY OF THE DOUBLETRACK SITE AND SURROUNDING AREA
}

\author{
CENTRAL NEVADA
}

DATE OF SURVEY: DECEMBER 1993

T. J. Hendricks

Project Scientist

REVIEWED BY

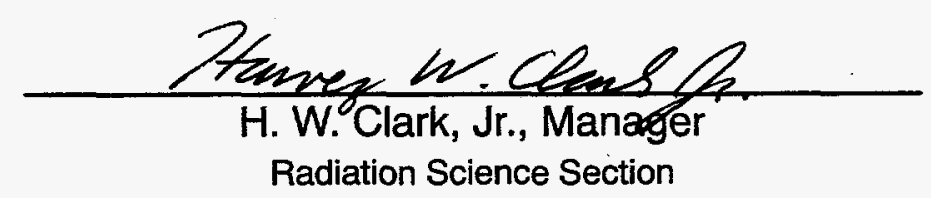

This Document is UNCLASSIFIED

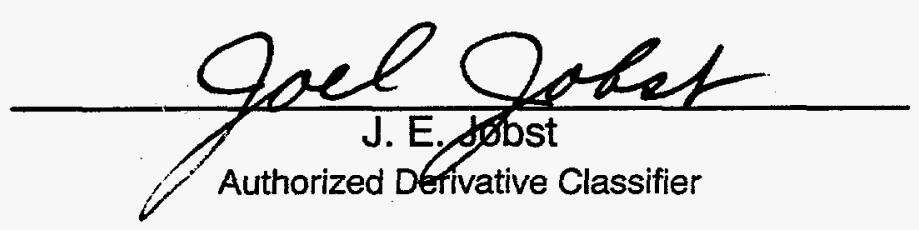

This work was performed by EG\&G/EM for the United States Department of Energy under Contract Number DE-AC08-93NV11265. 
An aerial radiological survey of the Double Track Site was conducted in December 1993. An interim report entitled "An Aerial Radiological Survey of the Double Track Site and Surrounding Area," EGG 11265-1086, was issued. That report described survey procedures and presented terrestrial exposure rate and wide-area-averaged plutonium isopleth plots. This letter report presents additional plutonium plots and some "rule-of-thumb" calculations which should help the reader to properly interpret the data presented.

Attached to this report are three isopleth plots produced from the Double Track data. No one processing method provides all the answers regarding a particular surveyed area. Where peak values are most important, Figure 1, created from the original unsmoothed data, is the presentation of choice. Figure 2, from smoothed data, is superior for the detection of areas of widespread low-level contamination. Figure 3, also smoothed data, satisfied a particular early mission goal but is not as useful for cleanup operations as the other two. Figure 3 is presented for historical completeness only.

\section{$2.0 \quad$ DATA}

\subsection{Unsmoothed (C:iginal) Data}

The isopleth presented in Figure 1 was generated from the as-measured data using the original second-by-second position and concentration values. Nominal line spacing for the data set was 150 feet, nominal along-track spacing was 120 feet, and nominal altitude was 100 feet. No averaging, smoothing, or gridding was done.

Data processed in this manner gives the best possible spatial resolution and best possible determination of concentration in small areas. This latter point is very important. If a contaminated area is small with respect to the detector's field-of-view, then the maximum concentration in that area (peak value) is averaged with surrounding lower values, which results in underestimation of the actual concentration. It also causes the contaminated area to appear larger than it should.

Smaller detector footprints minimize this characteristic, but at a significant cost to sensitivity. The second-by-second acquisition time yields rather poor counting statistics; therefore, the method does not have good sensitivity for low-level, wide-area contamination.

It should be noted that even the as-measured data of Figure 1 does not necessarily produce an accurate representation of ground-level conditions. Simple relationships describe the effect that a given detector spatial response will have on a given input. While the relationships are exact only for Gaussian-shaped functions, actual functions approximate the Gaussian well enough that the relationships are applicable for most estimate purposes. 
The first equation relates widths of the involved functions:

$$
\begin{aligned}
& \text { OW }=\left((\mathrm{IW})^{2}+(\mathrm{RW})^{2}\right)^{12} \\
& \text { where } \\
& \text { OW }=\text { observed full width at half max (FWHM) } \\
& \text { IW }=\text { input (ground deposition) FWHM } \\
& \text { RW }=\text { detector point source response FWHM }
\end{aligned}
$$

The second equation relates peak and width relationships:

$$
\mathrm{OP} / \mathrm{IP}=\mathrm{IW} / \mathrm{OW}
$$

where

$\mathrm{OP} \quad=$ observed peak amplitude

IP = input (ground deposition) peak amplitude

As an illustration, consider the following set of parameters:

Assume a detector response FWHM $=200$ feet (approximate value for 100 foot altitude).

Assume a ground deposition (input) FWHM $=300$ feet

From (1), the observed FWHM will be:

$$
\text { OW }=\left((300)^{2}+(200)^{2}\right)^{1 / 2}=361 \text { feet }
$$

From (2), the observed peak value multiplier will be:

$$
\mathrm{OP} / \mathrm{IP}=\mathrm{IW} / \mathrm{OW}=300 / 361=0.831
$$


The following table was generated using (1) and (2) with an assumed detector response (RW) of 200 feet (assumed altitude 100 feet).

$\begin{array}{llll}\begin{array}{l}\text { INPUT } \\ \text { (GROUND }\end{array} & \begin{array}{l}\text { OBSERVED } \\ \text { FWHM }\end{array} & \begin{array}{l}\text { RELATIVE } \\ \text { PEAK }\end{array} & \begin{array}{l}\text { PEAK } \\ \text { CORRECTION }\end{array} \\ \begin{array}{l}\text { FWHM } \\ \text { (IW IN FEET) }\end{array} & \text { VALUE } & \\ & \text { (OW IN FEET) } & \text { (OP/IP) } & \text { (IP/OP) } \\ 2 & & & \\ 5 & 200.0 & 0.0100 & 100.0 \\ 10 & 200.1 & 0.0250 & 40.02 \\ 20 & 200.2 & 0.0500 & 20.02 \\ 50 & 201.0 & 0.0995 & 10.05 \\ 100 & 206.2 & 0.2425 & 4.124 \\ 200 & 223.6 & 0.4472 & 2.236 \\ 500 & 282.8 & 0.7071 & 1.414 \\ 1000 & 538.5 & 0.9285 & 1.077 \\ 2000 & 1020 . & 0.9806 & 1.020 \\ & 2010 . & 0.9950 & 1.005\end{array}$

Note that for narrow input FWHM, the observed FWHM is essentially that: of the detector response function. Within normal field measurement tolerances (about $+/-(5 \%)$ ), virtually no information exists in such observed data to define the input width other than that it appears to be equal to or less than 50 feet FWHM and that the peak correction value is greater than 4.124. For a source of extent less than one inch, the peak correction value could exceed three orders of magnitude! Only for input FWHM in excess of 500 feet can the detector spatial response function be considered negligible.

For observed widths differing by a reasonable amount from the detector response function width, estimates can be made of the true input width and peak correction factor. From the data used to generate Figure 1, over the area of peak activity, the measured FWHM was 270 feet and the peak value was $1443 \mathrm{pCi} / \mathrm{gm}$. Rearranging (1) and (2), and solving for the apparent input parameters gives:

Estimated input width is:

IW $=\left((\mathrm{OW})^{2}-(\mathrm{RW})^{2}\right)^{12}$
IW $=\left((270)^{2}-(200)^{2}\right)^{12}$
IW $=181$ feet


and estimated input peak is:

$$
\begin{array}{ll}
\text { IP } & =(O W / \mathrm{OW}) * \mathrm{OP} \\
\mathrm{IP} & =(270 / 181) * 1443 \\
\mathrm{IP} & =2152 \mathrm{pCi} / \mathrm{gm}
\end{array}
$$

One may also calculate the uncertainty of the estimate. As previously mentioned, the uncertainty of the observed FWHM is approximately $+/-(5 \%)$, so that the observed width becomes $181+/-(5 \%)$ or 172 to 190 feet. Using (2a) to calculate corresponding peak values gives:

$\min \mathrm{FWHM}=172$ feet, $\max$ peak $=2265 \mathrm{pCi} / \mathrm{gm}$ (round to 2300 )

$\max \mathrm{FWHM}=190$ feet, min peak $=2050 \mathrm{pCi} / \mathrm{gm}$ (round to 2000)

NOTE: Four digits were carried in parameters of the examples to precisely illustrate changes and relative values associated with the estimation technique. This does not imply four-digit accuracy in any real value. The estimated peak ground deposition is appropriately stated to only two digits as "2000 to. 2300 PCI/GM."

\subsection{Smootheí Data: Sample Grid of 150-foot Elements, 9-point Neighbor Averaging}

The isopleth presented in Figure 2 was created using a new analysis algorithm. This algorithm averages data over a region significantly larger than the detector's field-of-view. This substantially increases the measurement sensitivity, but at a cost of reduced spatial resolution and aggravated underestimation of the peak value.

The original second-by-second data were resampled to create a grid with 150 -foot elements. This grid matches the nominal original line spacing and is reasonably close to the nominal along-track point spacing. The gridded data are averaged so that each element of the grid is the average of the nine nearest neighbors. Isopleths were generated using this averaged data within the 150 -foot grid elements.

Use of the averaging technique greatly improves low-level statistical uncertainty and allows setting of lower-level detection limits for areas of widespread low-level contamination. Spatial resolution is degraded, but the location of peak values is reasonably well preserved. Peak values from areas of contamination which are small with respect to the sampling neighborhood are underestimated more strongly than peak values from unsmoothed/averaged data. 


\subsection{Smoothed Data: Sample Grid of 450-foot Elements}

The isopleth presented in Figure 3 is a reproduction of the one informally distributed earlier and is essentially the same as that presented in the preliminary report. It was created utilizing the data smoothing algorithm which was the predecessor of that described above. This algorithm was designed to map widespread contamination associated with atmospheric nuclear testing with optimal sensitivity.

The algorithm assumes that the contamination is so widespread that it is relatively uniform over many times the detector's field-of-view. The original second-by-second data were resampled to create a grid of 450 -foot elements. Approximately 11 original points are averaged within each 450 -foot grid element. As previously discussed, such averaging improves detectability for widespread contamination areas. Isopleths were generated using the averaged data projected on the 450 -foot grid.

As with Figure 2, low-level detection limits are improved by this technique. However, peak values are not well preserved and an additional uncertainty exists in the location of the peak, because the spatial resolution can be no better than the resampled point spacing (450-foot).

The data set for Figure 3 was the first distrïuted because it generally is very conservative, showing contamination where there is even the slightest possibility of its presence. This was the perceived short-term goal of the surveys done at the Clean Slates and at Double Track. Later discussions led to the understanding that spatial resolution and improved determination of peak values were also very important.

\subsection{COMMUNICATION}

There are many useful other data products that can be generated from the aerial survey data. It is essential that communications exist between RSL scientific personnel and Double Track principals so that proper products may be provided and that proper interpretations may be applied to existing and future products. 


\section{NOTICE}

Page(s) size did not permit electronic reproduction. Information may be purchased by the general public from the National Technical Information Service, U.S. Department of Commerce, Springfield, VA 22161 (Area Code 703-487-4650). DOE and DOE contractors may purchase information by contacting DOE's Office of Scientific and Technical Information, P.O. Box 62, Oak Ridge, TN 37831, Attn: Information Services (Area Code 423-576-8401). 